\title{
NA TRILHA DOS FEMINISMOS: LEI MARIA DA PENHA, EXTENSÃO UNIVERSITÁRIA E A CONSTITUIÇÃO DE NOVOS ATORES SOCIAIS NO ENFRENTAMENTO ÀS DESIGUALDADES DE GÊNERO
}

\author{
IN THE TRACK OF FEMINISMS: MARIA DA PENHA LAW, ACADEMIC \\ EXTENSION AND THE CONSTITUTION OF NEW SOCIAL ACTORS TO FACE \\ GENDER INEQUALITIES
}

\author{
${ }^{1}$ Isadora Vier Machado \\ ${ }^{2}$ Crishna Mirella de Andrade Correa
}

\section{RESUMO}

Em uma cena de clara derrocada das estruturas de Estado que fundamentaram as políticas públicas de enfrentamento às violências contra mulheres, os feminismos brasileiros têm o desafio de reinventar suas reivindicações, para assegurar uma vida sem violências. Este trabalho tem por objetivo explorar uma experiência de extensão universitária que se consolidou para ofertar um núcleo de assistência jurídica gratuita para mulheres em situação de violências, mas que, a partir deste trabalho, também procura desenvolver estratégias de problematização das questões de gênero na pauta universitária. Destaca-se a importância das universidades como novos atores sociais de garantia cidadã.

Palavras-chave: Lei Maria da Penha; gênero; extensão universitária; cidadania.

\begin{abstract}
In a scene of clear overthrow of state structures that grounded public policies to confront violence against women, Brazilian feminists have the challenge of reinventing the path of claims to ensure a life without violence. This study aims to explore an academic extension experience that was consolidated at the university with the proposal to offer free legal assistance for women in situations of violence, but, from this work, also seeks to develop strategies for the problematization of gender issues on the university agenda. It is important to emphasize the role of universities as
\end{abstract}

Keywords: Maria da Penha Law; gender; academc extension; citizenship.

\footnotetext{
${ }^{1}$ Doutor em Ciências Humanas pela Universidade Federal de Santa Catarina (UFSC). Mestre em Direito, Estado e Sociedade pela Universidade Federal de Santa Catarina (UFSC) Florianópolis, Santa Catarina. Professora adjunta do Departamento de Direito Público da Universidade Estadual de Maringá (UEM) Maringá, Paraná, Brasil. Email : isadoravier@ yahoo.com.br ${ }^{2}$ Mestre em Direito pela Universidade Federal de Santa Catarina (UFSC), Doutoranda do Programa de Pós-Graduação Interdisciplinar em Ciências Humanas pela Universidade Federal de Santa Catarina (UFSC), Florianópolis, Santa Catarina. Professora adjunta do Departamento de Direito Público da Universidade Estadual de Maringá (UEM), Maringá, Paraná, Brasil. Email: tutortreinamneto@gmail.com
} 


\section{INTRODUÇÃO}

A Lei Maria da Penha (Lei 11.340/06), em seus dez anos de vigência, constituiu três dimensões de atuação fundamental (MACHADO, 2013), dentre estas, um eixo criminalizante, operacionalizado pelos sistemas de segurança e justiça, e que tem ocupado um potente espaço nos discursos feministas brasileiros desde a década de 1970 (v. também PASINATO, 2010). Entretanto, há que se destacar, também, a composição de um campo nominativo de ampliação da compreensão de violências, já que a lei, em seus artigos $5^{\circ}$ a $7^{\circ}$, além de categorizar a violência doméstica e familiar contra mulheres como uma violação de direitos humanos, também oportuniza o fortalecimento da rede de atendimentos para consolidar uma concepção de violências para além da violência física e, de igual modo, concebe-as enquanto questões de gênero (SCOTT, 1995). Para complementar a proposta tríplice, o documento normativo também alavancou um terceiro eixo de funcionamento - o do campo preventivo. Nesse aspecto, assim como as medidas protetivas de urgência previstas pela lei (arts. 22 e seguintes), seu art. $8^{\circ}$ destaca a importância de inserir nos currículos de educação formal as discussões sobre gênero.

Este trabalho tem por objetivo explorar uma experiência de extensão universitária que se consolidou com a proposta de ofertar um núcleo de assistência jurídica gratuita para mulheres em situação de violências, atendendo às dimensões nominativa e preventiva acima pontuadas. Trata-se do NUMAP/UEM (Núcleo de Extensão sobre a Lei Maria da Penha), um serviço permanente de escuta qualificada, composto por uma advogada recém-formada, três estagiárias do curso de Direito e uma estagiária do curso de Psicologia, todas vinculadas à Universidade Estadual de Maringá, no Paraná.

A experiência de advocacy feminista (LIBARDONI, 2000) não é inédita, nem sequer o são as atividades desempenhadas pelo grupo - peticionamentos; atendimentos; encaminhamentos; participação em audiências; mas também a elaboração de campanhas locais sobre violências; a composição paralela de um grupo de estudos sobre gênero e Direito; a articulação com outros níveis da educação formal (sobretudo o ensino médio), com a intenção de disseminar conhecimento sobre a Lei Maria da Penha; dentre outras estratégias que são concebidas e postas em prática de acordo com a conjuntura (orçamento, parcerias, novas ideias, demanda local, etc.). O que se propõe de novo, aqui, é a problematização sobre a importância das universidades como novos atores sociais que representam uma continuidade no tradicional processo de enfrentamento às violências de gênero. A extensão universitária 
pode ser capaz de reconfigurar o quadro interventivo estatal e fortalecer o âmbito de tradução dos discursos feministas (ALVAREZ, 2014), além de se levantar como um locus vital de resistência aos limites impostos desde o Judiciário ou Legislativo, principalmente.

\section{OS DESAFIOS POSTOS ÀS DEMANDAS FEMINISTAS}

Quem, de algum modo, já se aproximou do debate feminista, sabe que há uma propensão, em geral no Ocidente (sobretudo na Europa, nos Estados Unidos e Canadá), em organizá-lo sistematicamente em "ondas” (v. HEMMINGS, 2009, p. ex.). Entretanto, como bem nos lembra Naiara Andreoli Bittencourt (2015), este é apenas "um modo de ler e interpretar a construção do feminismo e das mulheres em âmbito global” (203:2915). No mesmo sentido, Joana Pedro (2011) destaca que essa divisão, nos países do Cone Sul, ganha novos contornos, já que a chegada de categorias que demarcam o lugar de cada onda (p. ex., a categoria mulher, na década de 1970; e a categoria gênero, na década seguinte) costuma ter aqui uma temporalidade distinta, além de não poder ser tão bem delimitada, porque há um certo vai-e-vem analítico que faz com que as lutas que conferem identidade às ondas feministas do norte global se estendam por muitos anos e perpassem períodos históricos distintos em nossa realidade local.

Além do que, a identificação metodológica dos feminismos com as ondas não se compatibiliza com necessidades históricas advindas de nosso processo de redemocratização ou com idiossincrasias geradas pelas acentuadas desigualdades entre as mulheres brasileiras (BITTENCOURT, 2015, p. 205).

Desse modo, a pauta reivindicatória do enfrentamento às violências, tradicionalmente identificada como a demanda central da Segunda Onda Feminista, ainda é reconhecida como premente no Brasil e não pode, de modo algum, ser lida como uma reivindicação superada, dada a evidência dos dados que ainda apontam índices altíssimos de violências (v., p. ex., o gritante número de feminicídios levantados por WAISELFISZ, 2012).

Por outro lado, se as "ondas vêm e vão e se sobrepõem; e, portanto, não são fases que terminam abruptamente" (WOLFF, 2015), é importante compreender que, ao longo das últimas décadas, a Lei Maria da Penha revigorou o debate sobre a temática em questão, em nosso país, inserindo nele um elemento fundamental - a categoria gênero.

A historicidade do enfrentamento às violências contra mulheres, no Brasil, pode ser buscada em várias fontes (v., p. ex., PEDRO, 2012). De forma sintética, costuma ter sua 
inauguração efetiva pontuada a partir da década de 1970, com a mobilização dos primeiros movimentos de mulheres. Das vozes e lutas de tais articulações, surge, em 1985, a primeira política pública de atendimento - a DEAM (Delegacia Especializada) de São Paulo (DEBERT et alie, 2006). A década de 1990 é marcada pela efetivação de documentos internacionais de enfrentamento à violência, sobretudo a conhecida Convenção de Belém do Pará, consolidando a transnacionalização das demandas para a efetiva atuação do Estado em prol da preservação da vida e integridade das mulheres (v. SANTOS, 2007). É nos anos 2000, contudo, que o Estado assume o efetivo protagonismo no enfrentamento às violências, com a atuação sistemática do Executivo Federal, consubstanciada na criação dos Planos Nacionais de Políticas para Mulheres (SPM, 2004), das Conferências Nacionais (SPM, 2016) e da criação e posterior alçada da Secretaria (outrora Especial) de Políticas para Mulheres à categoria de ministério.

A estrutura montada pelo Executivo Federal oportuniza a criação e disseminação de políticas por todo o país, comprometendo os demais entes da federação a assumir o protagonismo na estruturação dos serviços. O auge desse processo, sem sombra de dúvidas, foi a Lei Maria da Penha, que enunciou expressamente a necessidade de fortalecimento da rede de atendimentos (v., p. ex. arts. 8 , inc. I e $9^{\circ}$, da lei).

Em 2012, passados seis anos de vigência da lei, o Congresso constituiu uma Comissão Parlamentar Mista de Inquérito, para averiguar sua efetiva aplicação no território brasileiro (SENADO FEDERAL, 2012). Desse procedimento, sobressai uma crítica contundente ao Poder Judiciário, evidenciando um dos limites persistentes na proteção das mulheres em situação de violências. Soma-se a isso, obviamente, um crítico cenário de baixíssima implementação das instâncias previstas para o desejável funcionamento da rede delegacias especializadas, centros de referência especializados e juizados de violência doméstica e familiar, acima de tudo (PASINATO, 2010). Não bastassem as falhas pontuadas pela CPMI, a cena se agrava, recentemente, no palco do Legislativo e do Executivo Nacionais.

No campo do Legislativo, apenas para mencionar uma das negociatas que evidenciam o desmantelamento das políticas nacionais pelas quais as feministas brasileiras historicamente lutaram, pode-se destacar o processo de tramitação da Lei do Feminicídio (Lei 13.104/2015). Nota-se, no encaminhamento da proposta, como campo do gênero se converteu em uma cena central de embates, hoje, no Brasil. O feminicídio apareceria textualmente no Código Penal brasileiro como a morte das mulheres em razão do gênero. Porém, o que se vê 
na lei aprovada é a supressão da categoria gênero e sua substituição por sexo feminino, provavelmente para afastar a possibilidade de incidência da lei às travestis ou às mulheres trans (v. EL HIRECHE; FIGUEIREDO, 2015). Sem falar em outras propostas que pululam no Congresso, como o Projeto de Lei da Câmara, sob número 5069/2013 (CÂMARA FEDERAL, 2013), de autoria de Eduardo Cunha, que obstaculiza o atendimento e a plena assistências às mulheres em situação de violência sexual. Enfim, foi em 2015 que se ampliaram os debates nas Casas Legislativas estaduais e municipais propondo a retirada das discussões de gênero nos respectivos planos de educação.

Finalmente, no que tange ao Executivo Federal, o processo de impeachment da presidenta democraticamente eleita, além de destitui-la do posto de gestão, reconfigurou as pastas ministeriais sem a presença de uma mulher sequer à frente destas e esvaziou a estrutura ministerial da Secretaria de Políticas para Mulheres, que volta a ser "Especial", a partir de sua incorporação ao Ministério da Justiça, com a conseguinte perda da autonomia financeira e administrativa e esvaziamento orçamentário.

\section{LEI MARIA DA PENHA E UNIVERSIDADE: O PERCURSO DO NUMAP/UEM E A CENTRALIDADE DA PERSPECTIVA DE GÊNERO}

Em meio ao quadro acima delineado, em 2014, a Secretaria de Estado da Ciência, Tecnologia e Ensino Superior (SETI), do Estado do Paraná, lançou o edital 07/2014, como parte do Programa de Extensão "Universidade sem Fronteiras". De acordo com o edital, o objetivo seria "de viabilizar programas e projetos que possam fomentar atividades nas áreas estratégicas para o desenvolvimento sustentável", fortalecendo as ações de extensão e a articulação entre as universidades do Estado e a comunidade.

Oportunamente, havíamos obtido também a aprovação de uma proposta de pesquisa no âmbito do Edital Universal (MCTI/CNPq $n^{\circ}$ 14/2014), com financiamento público para "constituir equipe científica para mapear e analisar pontualmente as recentes configurações das instâncias da rede de atendimentos às mulheres em situação de violências, de Maringá/PR, desde 2012, a fim de otimizar a instrumentalização da Lei Maria da Penha na localidade, em benefício das mulheres que vivem em Maringá/PR e região”.

Além disso, desde 2015, coordenamos um grupo de estudos de gênero e Direito, como proposta de ensino vinculada ao curso de Direito da Universidade Estadual de Maringá (Projeto 6151/2015), cujo objetivo central consiste em promover a leitura e o debate de textos 
fundamentais para o campo de Estudos de Gênero, motivando, sobretudo, a reflexão correlata com o Direito, a fim de propor uma leitura deste campo teórico enquanto verdadeira tecnologia normativa de gênero (DE LAURETIS in HOLLANDA, 1994).

Diante disso, aproveitamo-nos da conjuntura, composta por financiamento público, constituição de uma equipe coesa de ensino e pesquisa, e de irrestrito apoio institucional, para tentar empreender também uma iniciativa de extensão universitária. De modo a cumprir com o mandato do art. 43, inc. VII, da Lei 9.394/1996 (Lei de Diretrizes e Bases da Educação Nacional), que atribui à extensão o propósito de tornar a universidade "aberta à participação da população, visando à difusão das conquistas e benefícios resultantes da criação cultural e da pesquisa científica e tecnológica geradas na instituição”.

Visávamos consolidar uma ação de advocacy feminista no sentido esposado por Marlene Libardoni (2000), como um mecanismo de ampliação cidadã das mulheres de Maringá e região, mas também como um meio de interferência nas políticas locais de promoção de igualdade de gênero.

[Com um] significado mais amplo, denotando iniciativas de incidência ou pressão política, de promoção e defesa de uma causa e/ou interesse, e de articulações mobilizadas por organizações da sociedade civil com o objetivo de dar maior visibilidade a determinadas temáticas ou questões no debate público e influenciar políticas visando à transformação da sociedade. (2000, p. 2)

Não se trata, portanto, única e exclusivamente da prestação de serviços advocatícios, e sim de articulações da sociedade civil para constituir um posicionamento coeso pela garantia dos direitos das mulheres, além da promoção de assistência jurídica. A iniciativa tem antecedentes históricos importantes no Brasil, como o Comitê Latino-americano e do Caribe para a Defesa dos Direitos da Mulher (CLADEM) que remonta à década de $1980^{3}$, ou a THEMIS - Gênero, Justiça e Direitos Humanos, criada em $1993^{4}$, apenas para exemplificar.

No Paraná, a Universidade Estadual de Londrina contava com projeto semelhante, desenvolvendo atendimento jurídico e apoio psicológico a mulheres em situação de violências. Além disso, havia também uma demanda latente na comarca, especialmente por

\footnotetext{
${ }^{3}$ « O CLADEM é uma rede feminista que trabalha para contribuir à plena vigência dos direitos das mulheres na América Latina e Caribe, utilizando o direito como um instrumento de mudança. Conta com status consultivo na Categoria II perante as Nações Unidas desde 1995 e goza de reconhecimento para participar nas atividades da OEA desde 2002 ». (CLADEM. Disponível em : http://cladem.org/po/sobre-o-cladem. Acesso em 10 set. 2016). ${ }^{4}$ A THEMIS - Gênero, Justiça e Direitos Humanos foi criada em 1993 por um grupo de advogadas e cientistas sociais feministas com o objetivo de enfrentar a discriminação contra mulheres no sistema de justiça. A história da THEMIS se confunde com as lutas e conquistas das mulheres brasileiras. Sua missão é ampliar as condições de acesso à justiça. É uma organização da sociedade civil com sede em Porto Alegre (RS/Brasil). (THEMIS. Disponível em : http://themis.org.br/somos/historia/. Acesso em 10 set. 2016).
} 
parte da juíza da vara criminal especializada, para implementar na localidade o mesmo modelo de atendimento.

A proposta consiste em aprimorar e consolidar a rede de atendimentos, nos termos da Lei Maria da Penha, especificamente no que tange à implementação de serviço de atendimento especializado que possa ajudar as instâncias oficiais - como a Delegacia, ou o Juizado de Violência Doméstica e Familiar (que, no caso da comarca, tem competência criminal exclusiva) a absorver a demanda cotidiana. Ao mesmo tempo, o projeto tem por proposta fortalecer a formação de acadêmicas e acadêmicos, colocando-as/os em contato com a comunidade, para que desenvolvam habilidades técnicas antes não motivadas pelo curso de graduação.

A ação de extensão conta com 3 bolsistas de graduação em Direito; 1 bolsista de graduação em Psicologia e 1 profissional recém-formada em Direito, habilitada para exercer a advocacia. O grupo mantem contato permanente com as instâncias da rede de atendimentos, ajudando a absorver a demanda da comunidade e garantir a efetividade do atendimento nos diferentes órgãos. Paralelamente a esta atuação, o núcleo conta com o grupo de estudos sobre gênero e Direito, em caráter permanente.

A despeito das dificuldades para inauguração do projeto, principalmente em virtude do contex to político do Estado do Paraná (v. BUSATO, 2016), que obstou o repasse imediato de recursos para funcionamento, a ação de extensão constitui-se enquanto uma verdadeira estratégia para, ao centralizar-se na efetivação da Lei Maria da Penha, poder falar de gênero dentro da universidade. A própria lei, em seu art. $8^{\circ}$, dita que: “A política pública que visa coibir a violência doméstica e familiar contra a mulher far-se-á por meio de um conjunto articulado de ações [...]” e, dentre as diretrizes, recomenda:

VIII - a promoção de programas educacionais que disseminem valores éticos de irrestrito respeito à dignidade da pessoa humana com a perspectiva de gênero e de raça ou etnia;

IX - o destaque, nos currículos escolares de todos os níveis de ensino, para os conteúdos relativos aos direitos humanos, à eqüidade de gênero e de raça ou etnia e ao problema da violência doméstica e familiar contra a mulher.

O que a experiência do núcleo tem provado é que, instrumentalizar a Lei Maria da Penha para, por conseguinte, contemplar discussões de gênero como categoria central na universidade, é um bom meio de "legitimidade" ante as perseguições políticas instauradas 
pelas discussões sobre a suposta "Ideologia de gênero", no contexto nefasto dos projetos da "Escola sem Partido" (v. MIGUEL, 2016).

O modo como o núcleo opera a categoria gênero para ampliar o campo de implementação da Lei garante, dentre outros aspectos relacionados ao atendimento, que a escuta qualificada se esquive de culpabilizar as mulheres, além de conferir-lhes a prerrogativa de decidir quais encaminhamentos preferem dar ao seu caso em particular. De igual maneira, busca-se conceber a violência em uma perspectiva complexa, que abarque opressões de outras ordens (classe, etnia, geração, identidade de gênero, orientação sexual, etc.) e tentar estabelecer parâmetros de encaminhamento que contemplem a rede, de forma articulada, para que seja possível proceder a um atendimento que corresponda à efetiva escolha das mulheres pelo seu próprio destino. (v. VENÂNCIO; MACHADO, 2016)

No contexto universitário, o núcleo tem servido como referência para articular demandas da comunidade interna. Assim tem acontecido, por exemplo, com as campanhas de prevenção ao trote sexista; com exibição de documentários; exposição de fotos; articulação com a Secretaria de Mulheres do Diretório Central Estudantil, etc. Iniciativas que abrem a linha para debater também a prática de LGBTfobia na universidade, ou contemplar outras linhas de enfrentamento, tendo havido, inclusive, uma iniciativa institucional por parte da reitoria para criar um comitê de enfrentamento às diversas formas de violência de gênero e étnico-raciais na UEM (UEM, 2016).

Isso nos tem mostrado que, embora o núcleo esteja pautado no atendimento das mulheres, serve como um meio reconhecido legitimamente pela comunidade universitária (e de fora da instituição universitária também) para contemplar ações de prevenção, enfrentamento e discussão sobre gênero no mesmo espaço. Não à toa, o Núcleo de Estudos sobre Gênero e Direito, na retaguarda teórica da ação de extensão, conta com participação frequente e massiva de alunas/os e ex-alunas/os de vários cursos da universidade. $\mathrm{O}$ grupo tem também estreita articulação com os demais coletivos que atuam no campo do gênero e, assim, participa ativamente dos variados eventos, assumindo protagonismo nas reflexões sobre o tema dentro do curso de Direito. 


\section{MOVIMENTOS SOCIAIS UNIVERSITÁRIOS E AS CORPOREIDADES PRESENTES COMO SUBSTRATO DAS AÇÕES VOLTADAS AO ENFRENTAMENTO DAS DESIGUALDADES DE GÊNERO}

Diante do aparecimento do número de projetos de extensão que se propõem a enfrentar as desigualdades de gênero nas universidades, verificamos que o NUMAP/UEM faz parte, na verdade, do contexto relacionado à entrada de novos sujeitos e sujeitas no ensino superior, de suas vivências no jogo entre os diversos tipos de opressão e empoderamentos frente à instituição, e das lutas pela afirmação de direitos e identidades que ocorrem nesse espaço. Assim, para pensar a universidade como ator social no âmbito da efetivação de políticas públicas de igualdade de gênero, é necessário refletir sobre as circunstâncias que colocaram esse tipo de ente jurídico na esfera de realização de direitos sociais e atendimento à comunidade.

Na literatura das políticas públicas no campo da sociologia, é possível encontrar abordagens com enfoque no papel do Estado como protagonista da política, e outras mais centradas na ação dos organismos locais (SOUZA, 2006). No que se refere à entrada desse tema dentro das universidades, vemos que esse movimento tem início com as pesquisas de especialistas do ensino superior sobre ações do Estado no campo das políticas públicas e não propriamente na definição da universidade como braço das políticas.

A partir daí, a primeira reflexão com a qual nos deparamos é sobre quais são os/as personagens e fatores que influenciam a composição das ações do Estado em torno dos direitos sociais, o que se remete, em última instância, à discussão sobre como se forma a opinião pública em torno das políticas.

O governo possui, então, um espaço de ação que é permeável às opiniões externas àqueles que têm o poder de tomada de decisão, como movimentos sociais e outros subsistemas, como é o caso da universidade.

É possível dizer, que enquanto espaço de pensamento e de coexistência de diferenças, o espaço universitário sempre se apresenta enquanto um organismo com potencial de voz dentro da opinião pública sobre as políticas, sobretudo se considerarmos que, de início, as/os pesquisadoras/es universitários atuaram como consultoras/es do Estado para a definição de suas pautas de políticas públicas e depois, esses mesmos pesquisadores/as começaram a articular eles/as próprios/as espaços de reflexão e crítica sobre as políticas, no entanto, não mais demandados/as pelo Estado, e sim, pelos próprios sujeitos que passaram a existir dentro da universidade. 
Nesse mister, Theodor Lowi (1972), um dos escritores clássicos das tipologias de políticas públicas explica que cada política pública recebe apoios e rejeições de acordo com as arenas diferenciadas pelas quais transitam. Portanto, as opiniões que as universidades externam sobre determinadas políticas e pressões que realizam sobre os governos centrais dentro dessa seara estão bastante relacionadas à presença dos/as sujeitos/as diretamente interessados/as na política, dentro do espaço universitário.

Podemos dizer, então, que a presença das mulheres no ensino superior deve ser considerada, por si só, um fator importante no surgimento de reivindicações de políticas para mulheres que vinham de dentro da universidade, assim como de solicitações de órgãos de atendimento às mulheres dentro dessas universidades. Para isso, não foi necessário que a universidade se constituísse formalmente como um espaço de consulta para a elaboração de políticas. Segundo Cohn (2004), a constituição de novos atores políticos depende muito mais das redes de relações e das novas funções que esses atores estabelecem, do que de sua previsão como ator político em documentos oficiais.

Assim sendo, Capella, ao analisar o estudo de Cohn, explica que:

Focalizando as relações entre esses grupos de atores na formulação de políticas públicas no governo americano, seu estudo buscou demonstrar uma maneira útil de examinar o processo político, revelando a existência de subunidades (subsistemas) como lócus do processo de discussão de temas específicos, construção de problemas públicos e formulação de soluções. Nos subsistemas, esse grupo de atores, que podem ser servidores públicos, grupos de interesse, pesquisadores acadêmicos, membros do Legislativo, representantes de governos locais, entre outros, estabelecem redes de relacionamento e utilizam estratégias de persuasão e barganha de forma a privilegiar seus interesses." (CAPELLA; BRASIL, 2015, p. 60)

Portanto, o processo de criação de grupos de pressão sobre políticas públicas na universidade, e consequentemente o surgimento de espaços de atendimento e efetivação dessas políticas nesse espaço não dependem, necessariamente, de um aval ou previsão legal do Estado para isso. Apesar do campo da efetivação depender, para se consolidar, em boa parte, de financiamentos oriundos do Estado.

Refletindo mais a fundo sobre o aspecto da presença de minorias sociais dentro da universidade, é preciso considerar que esses/as sujeitos/as quase sempre passam a ter direito a esse espaço devido a políticas reivindicadas no meio social por movimentos sociais que podem estar fora ou dentro do espaço universitário, como é o caso das ONGs feministas, que estão fora, e os coletivos universitários negros estudantis, que exercem pressão desde dentro. A articulação com o âmbito externo à universidade se torna fundamental, uma vez que, dentro 
do espaço universitário, algumas minorias são ainda muito invisíveis, como é o caso do/as alunos/as transexuais, negros/as, com deficiência, ou indígenas, apenas para exemplificar. Porém, em relação às mulheres, isso não mais ocorre. Segundo o portal Brasil (2015), as mulheres hoje compõem mais de $50 \%$ do contingente universitário do país. Então, enquanto, há algumas décadas, era necessário que as mulheres de fora da universidade lutassem pela sua entrada nesse espaço, hoje, as mais de 3 milhões de mulheres dentro da universidade se associam em coletivos e grupos de estudos para pressionar o Estado a elaborar políticas públicas para todas as mulheres (não somente as universitárias) e começam a estabelecer postos de atendimento às mulheres dentro do espaço universitário, como é o caso dos postos de atendimento à saúde da mulher e da Lei Maria da Penha nas universidades, por exemplo.

As demandas criadas para consubstanciar ações de enfrentamento às violências contra mulheres têm como desdobramento incontornável as discussões e práticas de enfrentamento contra outras violências relacionadas às identidades de gênero ou orientação sexual, porque inevitavelmente, a partir da Lei Maria da Penha, se dão centralizadas na categoria estruturante do documento legal, que é, justamente, gênero.

É evidente que a universidade como ator político de reivindicação e efetivação de políticas quebra com o paradigma tradicional para o qual a educação se constituía unicamente em espaço de reprodução dos esquemas de controle dos corpos (LOURO, 1997) e perpetuação das relações de opressão. A entrada dos Núcleos da Lei Maria da Penha nas universidades passa por um enfrentamento, nesse sentido, na medida em que se constitui na materialização da luta contra a violência de gênero, dentro de um espaço que foi, por muito tempo, de acesso exclusivo dos homens (notadamente os homens cisgênero e heterossexuais).

Um olhar mais aproximado sobre a relação sociedade/universidade nos revela que as diferentes relações que envolvam esses dois âmbitos onde a política se produz e se reproduz passou por diversas fases, segundo Chaia (1993). De início, as pessoas de dentro da universidade começaram a aderir aos movimentos sociais fora da universidade, na década de 1960, e trouxeram os aprendizados da militância para dentro das práticas universitárias. São decisões individuais, mas que acabam estabelecendo um fluxo de conhecimento e racionalidade da universidade para os movimentos e no sentido contrário, a entrada do aprendizado da prática militante na universidade por esses/as pesquisadores/as, que passaram a se engajar em movimentos sociais. Na década de 1970, o contato da universidade com movimentos que estão fora de seus muros colocam a necessidade de reformulação de suas práticas, currículos e princípios da educação no geral, o que acaba se refletindo na 
Constituição Federal de 1988 e outras leis ordinárias da educação, posteriormente. Nesse período, vemos ainda os institutos de pesquisas sociais e sindicais, como o DIEESE, contratando professores/as universitários/as para pesquisar e fornecer dados que subsidiassem determinadas lutas por políticas públicas encampadas por esses setores.

O intelectual surge então como um intermediário - um mensageiro - entre a universidade e a sociedade, ampliando as possibilidades de avanço e de eficiência de uma iniciativa de movimento sindical, que pretende também em foco gerador de informação e conhecimento. (CHAIA, 1993, p. 47)

Desde então, essa aproximação entre sindicato e pesquisadores/s procurava articular conhecimento e ação, que se constitui em um desafio ainda atualmente, principalmente para a área da extensão universitária, como é o caso de projetos como o NUMAP. Trabalhos fundamentados em instrumentais acadêmicos fornecidos a órgãos como o DIEESE, por exemplo, mostraram que:

De maneira não institucional, a universidade forneceu estudiosos que colaboraram para o avanço do movimento sindical, demonstrando que a academia não contribui apenas para a eficiência do governo ou da produção empresarial" (CHAIA, 1993, p. 48).

Na década de 1980, a universidade começa a produzir estudos sobre os movimentos sociais de modo especializado, versando sobre história dos movimentos sociais sobre criança e adolescente, história dos movimentos de mulheres e movimentos negros. Paralelo a isso, multiplicam-se os centros de pesquisa fora da universidade, como Cebrap, Cedec, Idesp. Outro fator que impulsiona a relação movimentos sociais e universidade são as reformas curriculares, algumas ocorridas após a constituição de 1988, que começaram a admitir discussões sobre movimentos sociais urbanos e rurais. Segundo Chaia (1993, p. 49), “de forma geral, todas as unidades da área de ciências humanas aprofundam o debate sobre cidadania e participação social e política, valorizando estes temas no currículo”. O mesmo movimento de mudança curricular acontece dentro das pós-graduações, com o objetivo de atender as pesquisas pessoais de professores/as e alunos/as. Chaia (1993) ainda mostra ainda que o movimento social como prática dentro da universidade começa através das associações de docentes e posteriormente se abre para movimentos específicos, como os movimentos feministas e movimentos negros.

A partir daí, os movimentos sociais passaram a ser absorvidos por intermedio dos 
coletivos e representatividade dos/as alunos/as em assuntos da universidade, inclusive tópicos sobre inclusão de grupos. Na área da extensão, passaram a ser oferecidos serviços de eixos onde as políticas públicas se mostravam insuficientes, como é o caso do NUMAP, que se introduz em algumas universidades como mais um reforço para a rede de atendimento às mulheres em situação de violência. Não raro, esses núcleos são compostos por pesquisadoras com passagem por Programas de Pós-graduação referenciados por aprofundar-se em pesquisas feministas, e alunas com engajamento em coletivos estudantis feministas, mostrando que a militância é um componente importante para que esse tipo de extensão funcione. Então, quanto mais a equipe tem contato com movimentos sociais da área, mais possuem consciência das dificuldades reais de implementação da política pública na qual está inserida. Além disso, pode agregar conhecimento sobre as pautas que são colocadas para o governo em relação àquela área de atuação, o que são elementos fundamentais para a adequação dos atendimentos à realidade social.

Os coletivos feministas estão presentes em grande número nas universidades, sobretudo na última década. Segundo o mapeamento mais completo disponível na web nessa área, o da Universidade Livre Feminista (MAMU, 2015), dos 9 coletivos feministas que existem no Paraná, 5 estão estabelecidos dentro da universidade e em sua descrição é possível notar que todos os 5 são promotores da Marcha das Vadias em suas cidades, evento diretamente relacionado à questão da violência contra as mulheres.

A presença de núcleos semelhantes ao NUMAP, dentro de algumas universidades, se origina, então, em um percurso que tem, inicialmente, a luta das mulheres pelo espaço da educação, pelo direito de serem alunas e professoras, e após incorpora as reivindicações de coletivos feministas e outros movimentos sociais de mulheres pelo envolvimento de mais atores sociais nas pautas de enfrentamento às violências de gênero, de um modo geral.

\section{CONSIDERAÇÕES FINAIS}

A experiência do Núcleo de extensão sobre a Lei Maria da Penha, na Universidade Estadual de Maringá, remete aos estudos feministas na medida em que estes passam a refletir sobre práticas de cidadania efetiva das mulheres no campo das políticas públicas e lutas por direitos.

A discussão se situa também em um contexto de entrada dos movimentos sociais na universidade, que se tornaram de extrema importância para impulsionar a entrada e 
permanência de minorias sociais nesses espaços e, acima de tudo, assumiram um protagonismo destacável no desenvolvimento de estratégias de advocacy feminista, atualmente, no Brasil.

Em parte, a reflexão sobre os coletivos feministas e por outro lado, a relação entre a formação das pesquisadoras na militância feminista são suportes fundamentais para que esses núcleos viessem a fazer parte da rede de atendimento às mulheres em situação de violência. Portanto, o movimento do Estado de ampliar os espaços formais de exercício dos direitos das mulheres, a partir do financiamento de Núcleos de atendimento dentro das universidades, está bastante relacionado à expansão da prática da advocacy feminista, que por sua vez, surge no seio dos movimentos sociais feministas e se expande para o ambiente universitário. Então, estamos falando de algo que se estabelece no espaço entre a ação governamental, a pesquisa acadêmica e prática militante.

Finalmente, o movimento de ação da advocacy feminista desde as práticas de extensão universitária passa a ser vital para a continuidade do processo de enfrentamento às violências de gênero, de um modo geral, já que vivenciamos um quadro de severa derrocada e arrefecimento das políticas de financiamento e de retrocesso em outros campos tradicionalmente acessados nessa mesma luta.

\section{REFERÊNCIAS}

ALVAREZ, Sônia E. Para além da sociedade civil: reflexões sobre o campo feminista. Cadernos Pagu, n. 43, ISSN 0104-83333. Campinas: 2014.

BITTENCOURT, Naiara Andreoli. Movimentos Feministas. Insurgência: Revista de Direitos e Movimentos Sociais, v. 1, n. 1, 2015, p. 198-210.

BRASIL. SPM. Legados da $4^{a}$ Conferência Nacional de Políticas para Mulheres em imagens. Brasília, 2016. Disponível em: https://issuu.com/4cnpm/docs/legados_spm_. Acesso em: 21 set. 2016

BRASIL. SPM. Plano Nacional de Políticas Para Mulheres. Brasília, 2004. Disponível em: http://www.spm.gov.br/assuntos/pnpm/plano-nacional-politicas-mulheres.pdf. Acesso em: 21 set. 2016. 
BUSATO, Paulo César; ANDRADE, Andressa Paula de; CARUNCHO, Alexey Choi (Orgs.). 29 de abril: reflexões sobre as manifestações no centro cívico de Curitiba. Curitiba: Leandro Ayres França, 2016.

CÂMARA FEDERAL. PL 5069/2013. Tipifica como crime contra a vida o anúncio de meio abortivo e prevê penas específicas para quem induz a gestante à prática de aborto. Disponível em: http://www.camara.gov.br/proposicoesWeb/fichadetramitacao?idProposicao=565882. Acesso em: 22 mai. 2016.

CAPELLA, Ana Cláudia Niedhardt; BRASIL, Felipe Gonçalves. "Análise de Políticas Públicas: uma revisão da literatura sobre o papel dos subsistemas, comunidades e redes. Novos Estudos: março, 2015

CHAIA, Miguel W. Universidade, formação e movimentos sociais. Ciclo de debates "Universidade na Cultura brasileira", maio/1993.

COHN, Maria da Glória. Empoderamento e participação da comunidade em políticas sociais. Saúde e Sociedade. V.13, n.2, p 20-31, maio-ago, 2004.

DEBERT, Guita Grin; GREGORI, Maria Filomena; PISCITELLI, Adriana (Orgs.). Gênero e distribuição da justiça: as Delegacias de Defesa da Mulher e a construção das diferenças. Campinas: PAGU:UNICAMP, 2006.

EL HIRECHE, Gamil Föppel; FIGUEIREDO, Rudá Santos. Homicídio contra a mulher: Feminicídio é medida simbólica com várias inconstitucionalidades. Disponível em: http://www.conjur.com.br/2015-mar-23/feminicidio-medida-simbolica-variasinconstitucionalidades. Acesso em: 23 mar. 2015.

HEMMINGS, Clare. Contando estórias feministas. Revista Estudos Feministas, v. 17. n. 1, 2009.

HOLLANDA, Heloisa Buarque de (Org.). Tendências e impasses: o feminismo como crítica da cultura. Rio de Janeiro: Rocco, 1994.

LIBARDONI, Marlene. "Fundamentos teóricos e visão estratégica da Advocacy". Revista Estudos Feministas, v. 8, n.2, p. 207-222, 2º semestre, 2000.

LOURO, Guacira Lopes. Gênero, sexualidade e educação. Uma perspectiva pósestruturalista. Rio de janeiro, Vozes: 1997. 
MACHADO, Isadora Vier. Da dor no corpo à dor na alma: uma leitura do conceito de violência psicológica da Lei Maria da Penha. 282 f. Tese (Doutorado Interdisciplinar em Ciências Humanas). Programa de Pós-Graduação Interdisciplinar em Ciências Humanas. Universidade Federal de Santa Catarina, Florianópolis, 2013.

Mapeamento dos coletivos feministas no Brasil, MAMU, 2015. Disponível em: mamu.net.br. Acessado em 15 de maio de 2016.

MIGUEL, Luis Felipe. Da "doutrinação marxista" à "ideologia de gênero" - Escola Sem Partido e as leis da mordaça no parlamento brasileiro. Direito \& Práxis. v. 7. n. 15, 2016.

PASINATO, Wânia. Juizados Especiais de Violência Doméstica e Familiar contra a Mulher e a Rede de serviços para atendimento de mulheres em situação de violência em Cuiabá, Mato Grosso. Salvador: NEIM/UFBA, 2010.

PEDRO, Joana Maria. Nova história das mulheres no Brasil. São Paulo: Contexto, 2012.

Relações de gênero como categoria transversal na historiografia contemporânea.

Revista Topoi. v. 12, n. 22, jan.-jun. 2011, p. 270-283.

SANTOS, Cecília Macdowell. Ativismo jurídico transnacional e o Estado: reflexões sobre os casos apresentados contra o Brasil na Comissão Interamericana de Direitos Humanos. Sur: Revista Internacional de Direitos Humanos, n. 7, ano 4, 2007.

SCOTT, Joan. Gênero: uma categoria útil de análise histórica. Educação \& Realidade. Porto Alegre, v. 20, nº 2, jul./dez. 1995.

SENADO FEDERAL. Relatório final. Comissão Parlamentar Mista de Inquérito: com a finalidade de investigar a situação da violência contra a mulher no Brasil e apurar denúncias de omissão por parte do poder público com relação à aplicação de instrumentos instituídos em lei para proteger as mulheres em situação de violência. Brasília: 2012, p. 8. Disponível em: http://www.senado.gov.br/atividade/materia/getPDF.asp?t=130748\&tp=1. Acesso em: 14 jul. 2013.

SOUZA, Celina. Políticas Públicas: uma revisão da literatura;Sociologias, Porto Alegre, ano 8, n 16, jul/dez 2006, p. 20-45.

UEM. Reitoria autoriza criação de comitê permanente para enfrentamento à violência. Disponível em: v. http://www.ddp.uem.br/2016-04-26-13-26-32/18-pagina-principal/26- 
reitoria-autoriza-criacao-de-comite-permanente-para-enfrentamento-a-violencia. Acesso em: 21 set. 2016.

VENÂNCIO, Karen Eduarda Alves; MACHADO, Isadora Vier. A importância da categoria "gênero" para instrumentalizar o atendimento a mulheres em situação de violência no projeto NUMAP/UEM. IV Simpósio Gênero e Políticas Públicas. Londrina: Universidade Estadual de Maringá, 2016.

WAISELFISZ, Julio Jacobo. Mapa da violência 2012: Caderno complementar 1 - homicídio de mulheres no Brasil. São Paulo: Instituto Sangari, 2012. Disponível em:

http://www.mapadaviolencia.org.br/pdf2012/mapa2012_mulher.pdf. Acesso em: 11 jun 2015.

WOLFF, Cristina Scheibe. A UFSC explica: feminismo. Disponível em:

http://noticias.ufsc.br/2015/11/ufsc-explica-feminismo/. Acesso em: 21 set. 2016. 